\title{
Jornalismo, ativismo e sensibilidade hacker: ${ }^{1}$
}

\section{Por uma prática situada que ousa dizer o nome}

\section{Journalism, activism and hacker sensitivity:}

\section{For a situated practice that dares to say the name}

\section{Fabiana Moraes}

Professora e pesquisadora do Núcleo de Design e Comunicação Social da Universidade Federal de

Pernambuco - Centro Acadêmico do Agreste (UFPE/CAA) Universidade Federal de Pernambuco, Núcleo de Design e Comunicação Social, Nova Caruaru (PE), Brasil.

\section{Introdução}

Este artigo aponta para uma busca prática e teórica que traz à tona a importância do jornalismo que preza também por sua dimensão subjetiva. Nele, uma perspectiva ativista na produção da informação não é percebida como algo menor, que macula um enquadramento, que diminui uma mirada: antes, entendemos que o ativismo é algo pertinente ao jornalismo, seja ele localizado no literário, público, investigativo, etc. ("gavetas" questionáveis que, veremos, traçam significativas hierarquias profissionais e de conteúdo). Moraes (2018) trouxe recentemente a discussão sobre um jornalismo de subjetividade feito por um sujeito cognoscente (VEIGA, 2019) que não se neutraliza, que demonstra sua fala situada (HARAWAY, 1995). Este jornalismo que não nega sua dimensão subjetiva pode promover a quebra de representações, repensar valores-notícia excludentes e, finalmente, se abrir a uma prática ativista, não a entendendo como algo possível apenas em um ambiente digital, "independente", "alternativo", como se

\footnotetext{
${ }^{1}$ Texto apresentado na SBPJOR/Associação Brasileira de Pesquisadores em Jornalismo, 17o Encontro Nacional de Pesquisadores em Jornalismo, Universidade Federal de Goiás (UFG) em novembro de 2019. Aqui, segue com modificações.
} 
convencionou a pensar. Esse ativismo, ação delicada, pode estar localizado também no cotidiano de grandes empresas jornalísticas, em matérias cotidianas ou grandes reportagens, em editorias de cultura ou política, dentro daquilo que Russell (2016) chamou de uma "sensibilidade hacker". Ampliamos aqui essa ideia, sobre a qual falaremos em breve.

A mescla ativismo e jornalismo ganhou nos últimos anos uma enorme relevância no cotidiano nacional após uma série de reportagens realizadas pela equipe do site jornalístico The Intercept Brasil (TIB). As matérias da chamada Vaza Jato são baseadas em arquivos passados anonimamente que destacam, entre outros temas, as relações legalmente questionáveis ou não permitidas entre Ministério Público Federal de Curitiba e o então juiz Sérgio Moro no caso da Lava Jato².

Antes, é importante dizer que a temática ativismo/jornalismo não é nova nas discussões acadêmicas: análises focando ambientes digitais e/ou alternativos (ANTOUN, 2008; MORAES, 2007; PRUDÊNCIO, 2011) ou ainda relacionadas a questões como imprensa e feminismo (WOITOWICZ, 2014) compõem a farta literatura sobre o tema, assim como o clássico livro de Kucinski (2001) sobre parte da imprensa alternativa brasileira. Também há uma boa produção que trabalha com noções como a de “jornalismo cidadão” (TARGINO, 2009) na qual há diversos elementos relacionados ao ativismo jornalístico.

Porém, no contexto político brasileiro no qual ineditamente se misturam um governo executivo de ultra-direita, uma imprensa em parte fiadora do último e outra constantemente atacada (ainda que parte dela tenha contribuído bastante para a ascensão do primeiro), o jornalismo "parcial" ou "ativista" tornouse debate comum entre milhões de pessoas. Além da atualidade do tema, há outra questão que mobiliza este escrito: pensar o ativismo no jornalismo disperso também em estruturas, como dito, não necessariamente digitais ou "alternativas", mas também na imprensa localizada como hegemônica.

A noção geral, senso comum, de um jornalismo que precisa ser neutro e imparcial está de acordo com uma falácia propagada durante décadas a partir do próprio campo. Este se construiu o mais próximo

\footnotetext{
${ }^{2}$ A Operação Lava Jato teve início em 17 de março de 2014 no Paraná. A investigação sobre corrupção unificou quatro ações que apuravam redes operadas por doleiros que praticavam crimes financeiros com recursos públicos. "O nome Lava Jato era uma dessas frentes iniciais e fazia referência a uma rede de postos de combustíveis e lava a jato de veículos, em Brasília, usada para movimentação de dinheiro ilícito de uma das organizações investigadas inicialmente" (http://arte.folha.uol.com.br/poder/operacao-lava-jato/\#capitulo1, acesso em 23 de julho de 2019). As reportagens do The Intercept, publicadas desde o dia 9 de junho de 2019 e que mostram irregularidades também no julgamento do ex-presidente Inácio Lula da Silva, estavam em sua "parte 11" no momento da escrita desse texto, em julho de 2019. Elas podem ser lidas em https://theintercept.com/series/mensagens-lava-jato/. Acesso em 25/05/2020.
} 
possível de um rigor científico, do verificável, do que se pode provar (MEDINA, 2008; VEIGA, 2014), uma forma de garantir ao público que as paixões de um jornalismo partidário, apaixonado, tão ao gosto daquele visto na Europa do século 18 (THOMPSON, 2010) ou no Brasil colônia (SODRÉ, 1998) ficara, com suas "contaminações" e falta de rigor, para trás. Mas o fato é que não apenas o público ainda carrega fortemente o mito do jornalista objetivo: mesmo jornalistas de longa experiência, profissionais com prática em reportagem, gênero que comumente nos presenteia com as limitações das noções de pureza, isenção e objetividade, também acreditam na distinção entre um jornalismo ativista e um jornalismo isento, entre um profissional que é dominado por suas paixões e outro que as controla e não as deixa repercutir em seu trabalho. A título de ilustração, trazemos aqui exemplos colhidos em junho de 2019 no microblog Twitter, bastante usado pelos profissionais do jornalismo e, mais do que nunca, por figuras públicas de grande relevância política.
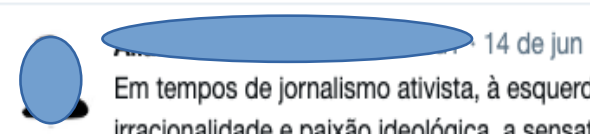

Em tempos de jornalismo ativista, à esquerda ou à direita; em tempos de pura irracionalidade e paixão ideológica, a sensatez de Clóvis Rossi fará muita falta

Q $1 \quad \uparrow \downarrow \begin{array}{llll}3 & 0 & 38\end{array}$

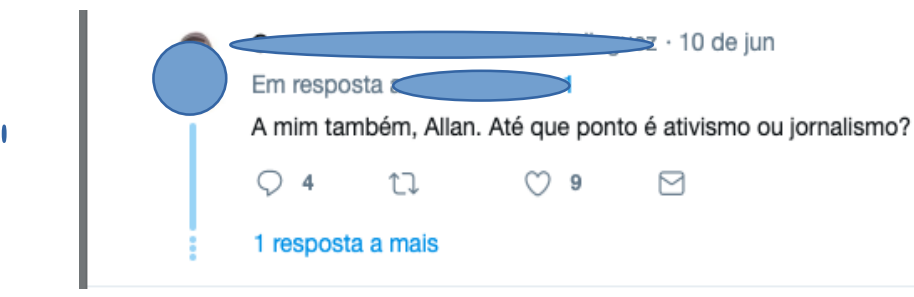

Figuras 1 e 2 - trocas de mensagens entre jornalistas no Twitter. Imagens extraídas pela autora

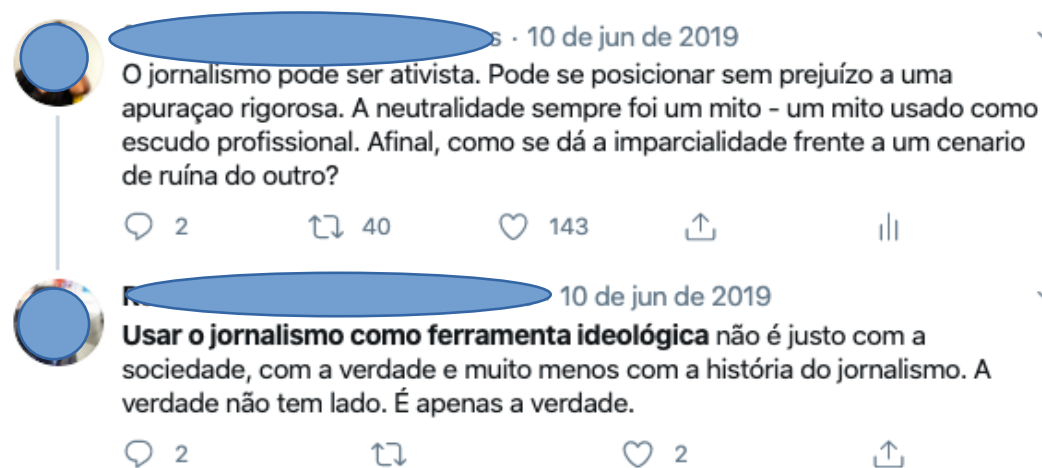

Figuras 3 e 4 - trocas de mensagens entre jornalistas no Twitter. Imagens extraídas pela autora 
As duas primeiras imagens foram extraídas das contas públicas de jornalistas da revista piauí, enquanto a terceira e a quarta imagem mostram mensagens trocadas publicamente entre um repórter do Correio Braziliense e uma jornalista e pesquisadora. Nos primeiros posts, irracionalidade e ativismo estão alinhados como pares: no que lamenta a morte do jornalista Clóvis Rossi (14 de junho de 2019), o pano de fundo eram as revelações sobre a Lava Jato publicadas no The Intercept Brasil. O segundo, uma resposta a um incômodo do primeiro repórter (que havia escrito anteriormente "A questão é: vale a pena cometer um ato imoral - divulgar conversas obtidas ilegalmente por um hacker - para desnudar atos imorais de pessoas públicas? Isso me perturba como jornalista"), segue o mesmo curso e faz a pergunta-chave que anima este texto. Na última imagem (4), temos a sugestão, de novo, de que há um jornalismo "ideológico" e outro "puro". As palavras usadas em todos são reveladoras: paixão ideológica; irracionalidade; ativismo; ideologia; sensatez; verdade. Estão expressas algumas das dicotomias clássicas dos estudos do jornalismo, objetividade versus subjetividade, pureza versus contaminação.

A partir de um estudo reflexivo das suas próprias práticas nas redações, Moraes (2015) discorreu sobre o que chama de jornalismo de subjetividade, termo que não nega a objetividade jornalística, mas que reconhece os aspectos subjetivos como necessários para uma prática mais íntegra e integral. Assim, a subjetividade é vista como um ganho fundamental na reportagem e mesmo na notícia cotidiana. Nela, são considerados, e não negados, os elementos que escapam da "rede técnica" desta área de conhecimento.

Desta rede, fazem parte: 1. a adesão a critérios do valor-notícia como personagens relevantes, proeminência dos fatos, localização geográfica, todos extremamente hierarquizantes ao nos dizer que algumas pessoas e lugares merecem ser vistos, outros não; 2 . a certeza em uma verdade única, apresentada pelo fato, sem levar em consideração que estes são construídos; ou seja, os acontecimentos não são vistos como sintoma, e seus relatos não buscam os fatores que provocam a explosão; 3 . pautas assentadas em fenômenos sociais não questionados ou em binarismos como a pobreza terrível ou "engraçada"; a negritude violenta ou vítima; a mulher frágil ou guerreira; etc.; 4. a crença de que o jornalista "dá voz", em lugar de ser um canal para vozes já existentes ecoarem.

O jornalismo de subjetividade ainda busca pela não exotificação de pessoas e grupos; pelo entendimento de uma escrita a partir de um lugar não neutro; por uma superação do elemento 
extraordinário; por uma produção que se dê antes pelas semelhanças e pelo encontro, não pela diferença (o jornalista como índice do "normal" que relata a vida de um outro "espetacular").

É preciso sublinhar que a subjetividade sobre a qual nos referimos neste jornalismo se irmana a critérios notadamente objetivos, mas que tantas vezes não são entendidos como tais: na necessidade de observarmos posições de classe, gênero, geográficas, raciais; na obrigatoriedade de levar em conta a estrutura social circundante na confecção de textos, imagens e outros produtos; na fissura de representações previamente dadas (ou fatos previamente dados e não conferidos e investigados); em uma autocrítica do próprio campo. Necessário dizer que a dimensão subjetiva também é conduzida ao lado de uma apuração rigorosa, análise de dados, pesquisas bibliográficas e de campo, observação direta ou indireta, etc.

\section{O jornalismo investigativo - isento? - como consagração máxima}

As distinções binárias observadas na produção jornalística (que remetem a uma lógica cartesiana do neutro/contaminado; objetivo/subjetivo; razão/emoção) se estabeleceram não só no público em geral e nas redações, mas são ensinadas e ampliadas no âmbito acadêmico. Nos cursos de jornalismo/comunicação, existem as disciplinas voltadas, por exemplo, para o jornalismo comunitário, o jornalismo popular, o jornalismo independente, o jornalismo público, o jornalismo literário. Certamente, existem questões, estratégias e abordagens que caracterizam as formas várias de fazer jornalismo - aqui, no entanto, queremos chamar atenção para o fato de que tais nomeações (comunitário, independente, literário, etc.) tratam de lugares nos quais a existência de práticas consideradas "ativistas" ou "subjetivas" estão até certo ponto permitidas. São jornalismos importantes, mas não chegam a ser aquele visto como o jornalismo maiúsculo, o investigativo. Assim, cria-se o espaço de uma outra forma de fazer jornalismo, um outro lugar, no qual - agora sim - as paixões e "ideologias" devem ser deixadas de lado para que se produza essa notícia/reportagem pura, isenta, neutra. A se pensar: qual seria o nome dessa disciplina "outra", a objetiva, a não contaminada?

O fato é que o jornalismo empresarial, das redes e conglomerados mais assentados, contém, para público e parte dos jornalistas, uma tão celebrada quanto frágil ideia de universalidade, constituindo-se como a norma. Tudo aquilo que não está nesse jornalismo universal seria, assim, um desvio, uma 
anormalidade situada (VEIGA, 2019) que se revela na pergunta da jornalista da revista piauí: “É jornalismo ou é ativismo?". Essa questão tem relação forte, inclusive, com a forma com a qual o próprio The Intercept foi tratado por parte da imprensa no momento primeiro dos vazamentos, quando preferiu chamar o veículo simplesmente de "site" como uma forma de marcar distinção. Essa perspectiva anacrônica passou a se modificar a partir do momento em que as empresas maiores e já sólidas na cultura nacional, a exemplo de Veja, Folha de S. Paulo e BandNews, se atrelaram ao TIB e passaram a divulgar o conteúdo de mensagens do aplicativo Telegram em parceria com a equipe do veículo. Essa disputa profissional revela, é importante trazer, questões a respeito do próprio jornalismo investigativo, um termo indefinido que, como observou Melo (2015, p. 145), é também sinônimo de sucesso profissional, com o próprio termo "investigativo" alimentando "imaginários de 'cruzadas', riscos, trabalho meticuloso". Em sua pesquisa, a autora identifica pelo menos três usos diferentes dessa especialidade jornalística, que surge como sinônimo de grande reportagem, identificada com o jornalismo policial ou, mais recentemente, relacionada ao escândalo político. Melo constata que as diferentes apropriações são reveladoras de disputas internas e externas ao campo jornalístico, algo que fica evidente no caso do TIB (e como veremos em Russell, mais à frente).

É importante também chamar atenção para uma outra questão que permeia as hierarquizações presentes nos "jornalismos" (literário, investigativo, etc): a distinção de pautas e temas a partir do gênero. Esse fenômeno foi profundamente abordado por Veiga (2014, p. 253), que observou o cotidiano de jornalistas no fazer noticioso diário e, ali, viu que "pauta para homem é uma coisa, para mulher, outra".

As matérias relativas aos dramas sociais, as chamadas 'soft news', as brincadeiras e as piadas em geral eram pensadas para repórteres do sexo feminino, ou para homens que não apresentassem perfil associado a atributos tidos como masculinos (ativo, forte, autônomo, investigativo) [...] Na hierarquia das notícias, as principais matérias eram as fortes, relacionadas ao investigativo, ao risco, etc., isto é, aos assuntos "sérios". E para este tipo de notícia, os jornalistas propostos eram preferencialmente do sexo masculino, e com determinadas características de gênero consolidadas e reconhecidas por seus pares (p. 254, itálico nosso).

Como trouxe Veiga, as mulheres ou homens sem os atributos percebidos socialmente como masculinos, no jornalismo (assim como no próprio imaginário social), estarão mais relacionadas ao emotivo, ao delicado, ao lúdico. O termo "frieza", aliás, é um dos levantados pelo jornalista Leandro Fortes em seu livro sobre jornalismo investigativo, como aponta Melo (2015). É claro que existem dezenas de jornalistas mulheres no Brasil reconhecidas por suas investigações, mas aqui chamamos atenção tanto para a prevalência masculina nesta prática quanto para as temáticas entendidas como "investigativas" e 
"masculinas" (política, economia) aparecerem em detrimento de outras, "femininas" (cultura, lazer, saúde) (VEIGA, 2014).

Nesse sentido, e estendendo mais um pouco essas distinções-hierarquias, há também, tanto na academia quanto nas redações, diferentes formas de tratar a noção do que é político. De maneira geral, os jornalistas (e público) não vão considerar como tais questões que não circulem especificamente nas editorias que cobrem a política partidária, institucional, os assuntos referentes a Brasília e o Planalto Central, os salões do poder judiciário, as assembleias legislativas, as prefeituras, etc. São distinções que seguem a tradição de dividir temas jornalísticos em cadernos/áreas/sessões: Cultura, Esportes, Beleza, Viagem, Cotidiano, Economia, etc. Há, é claro, uma hierarquia entre tais editorias, uma hierarquia da qual fazem parte também aqueles que são repórteres considerados "investigativos" e "os outros". De saída, essa divisão causou uma espécie de desfocado em uma enormidade de assuntos que são da ordem política cotidiana (no limite, o que não seria?), mas que foram construídos como pautas "sociais", dos "direitos humanos", "lúdicos", de "entretenimento". Assim, o jornalismo investigativo que é entendido como tal é aquele que geralmente aborda questões da política institucional; que apresenta o máximo de objetividade; que entrevista/investiga nomes proeminentes da agenda política. Um jornalismo mais “masculino”, portanto (VEIGA, 2014).

\section{Ativismo e subjetividade}

A ideia de um jornalismo "isento" em oposição a um jornalismo contaminado pelo ativismo é uma falácia que esconde principalmente as práticas permeadas por interesses do primeiro, o que se coloca como neutro, discurso forte no jornalismo das grandes empresas. Aqui a premissa da objetividade se coloca, como repara Christofoletti (2008, p. 92), "como um ritual estratégico que preserva o profissional de críticas à qualidade de seu trabalho, de questionamentos a sua legitimidade, de acusações de parcialidade em uma cobertura". Assim, criou-se a ideia de que há o bom jornalismo e o "jornalismo engajado", com o primeiro ocupando melhor posição hierárquica, e o segundo devendo ser desconsiderado. Este é feito por apaixonados demais por suas causas, o que os leva a não realizar um bom trabalho - a emoção, entendida como característica feminina, novamente surgindo como uma erva daninha na prática jornalística. Mas um jornalismo que reúne informação, boa apuração, enquadramentos não viciados e temas sociais urgentes 
(estejam eles na política institucional, nas coberturas ricas à beira-mar, nas favelas, nas escolas municipais, na música ouvida pelos jovens, etc.) é algo para ser evitado ou perseguido?

A questão de uma falta de objetividade relacionada a práticas ativistas surge frequentemente entre vários daqueles profissionais já estabelecidos no campo, como aponta Russell (2016) e como vimos nas críticas dos experientes profissionais da revista piauí. Segundo a autora, os críticos de novas formas de jornalismo recorrem facilmente "à noção de objetividade para argumentar que o profissionalismo está sendo violado, apontando o dedo para o que eles vêem como vagos os padrões dos novos atores no campo do jornalismo" (RUSSELL, 2016, p. 112). A autora se aprofundou, entre outros exemplos, em movimentos como o Occupy NY e nas reportagens publicadas por Laura Poitras e Glenn Greenwald no jornal britânico The Guardian a respeito de programas secretos de vigilância da Agência de Segurança Nacional (NSA) norte-americana vazados por Edward Snowden (não deixa de ser uma interessantíssima coincidência que o mesmo jornalista, Greenwald, esteja no cerne da discussão sobre a prática jornalista brasileira poucos anos depois). Russell (2016) percebe que, apesar das disputas do campo - aqui, chamamos atenção para pensar em emagrecimentos salariais, demissões e outros aspectos que tornam essa disputa mais dramática -, é possível detectar uma "sensibilidade hacker" não só em jornalistas, mas em uma extensa camada da população em rede:

Embora o rótulo hacktivista ainda esteja reservado para uma marca de ativismo de elite e tecnologicamente sofisticada, as sensibilidades do hacktivismo ${ }^{3}$ são muito mais comuns e moldam significativamente a ação política e social de hoje. Quando o público publica uma crítica ou corrige uma notícia ou circula informações - uma foto, um vídeo, um arquivo de áudio, um tweet, um link - relacionadas a um evento de notícias, elas são executadas em um nível básico com a sensibilidade hacker. Quando eles fornecem comentários que alteram o significado de uma peça, ou adicionam uma trilha sonora, ou incorporam comentários ou links alternativos a um arquivo e o enviam para suas próprias redes de pessoas e não para canais tradicionais de produção e distribuição, eles são hackers. Quando os ativistas remixam discursos políticos ou conteúdo comercial para criticá-los, criam uma solução para barreiras de comunicação, ou mascaram sua localidade para se protegerem, eles estão agindo com base nas sensibilidades do hacktivismo (RUSSELL, 2016, p. 16-17)

Ela concebe esta sensibilidade como um conjunto de valores de uma ética hacker ${ }^{4}$ e as normas e práticas que essa ética alimenta. Esta sensibilidade tem relação intensa com a coletividade, o

\footnotetext{
${ }^{3}$ Na pesquisa "A atuação do WikiLeaks, de grupos hacktivistas e do Movimento Cypherpunk na reconfiguração do jornalismo investigativo", Albuquerque (2016, p. 16) informa a origem da nomeação: “Antônio (2013) e Knappenberger (2012) afirmam que o termo Hacktivismo foi lançado pelo grupo Cult of Dead Cow e significa uma mistura de 'hacker' com 'ativismo', sendo considerado também uma forma de ativismo cibernético. Hacktivistas têm e utilizam conhecimentos técnicos para praticar atividades hackers, como invadir sistemas e capturar informações sigilosas para agir em prol de algum objetivo não pessoal"

4 “A Ética Hacker é o termo que descreve os valores morais e filosóficos na comunidade hacker. O termo 'Ética-Hacker' foi atribuído ao jornalista Steven Levy conforme descrito no seu livro intitulado 'Hackers: Heroes of the Computer Revolution'
} 


\section{ALCEU}

compartilhamento e o engajamento, ações estabelecidas em rede em prol de movimentos democráticos. Importante dizer, por outro lado, que a própria palavra "hacker" carrega todo um estigma (exposto inclusive no caso da Vaza Jato): "a prática hacker, julgada como pirataria, é muitas vezes marginalizada ou mal compreendida na cultura popular como um grupo sub-cultural separada ou diametralmente oposta à sociedade em geral" (DIAZ, 2017, p. 36)

Especificamente em relação aos jornalistas, Russell (2016) entende que, ao problematizar o próprio jornalismo e a democracia, ao entendê-los como espaços que pedem por constantes ajustes, o profissional da informação, a produtora de notícias, passam a trabalhar, hoje, combinando as oportunidades apresentadas pelo novo ambiente expandido da mídia com as práticas jornalísticas já perpetradas. Esses jornalistas tradicionais também são ativistas ao se conectarem com os jornalistas hackers pelas mesmas motivações: busca por uma verdade (algo que Russell poderia complexificar em sua obra), em interpretações baseadas em evidências. Todos estão determinados a servir aos interesses dos públicos em rede. A ideia é melhor apresentada (em que se pese certo essencialismo) na frase-síntese do jornalista e advogado Glenn Greenwald, um dos profissionais estudados no livro da pesquisadora: "Não é uma questão de ser ativista ou jornalista, esta é uma falsa dicotomia. É uma questão de ser honesto ou desonesto. Nem todo ativista é um jornalista, mas todo real jornalista é um ativista" (RUSSELL, 2016, p. 109).

Aqui pedimos atenção para a necessidade de expandir a ideia de uma sensibilidade hacker que pode estar, entendemos, além da utilização de suportes tecnológicos. Uma prática ativista possível mesmo em redações mais orientadas ao conservadorismo; uma forma de fazer política no interior de editorias que não são vistas como lugares desse tipo de prática (esportes, cultura, turismo, etc). Esse caminho foi feito por Moraes (2015) em uma série de reportagens realizadas durante 20 anos em uma redação, trabalhos que traziam temas como racismo, feminicídio, transfobia, machismo, classismo. A autora observou, na prática, que questões urgentes e emergentes podiam ser trabalhadas a partir de uma perspectiva ativista sem prejuízos ao prezado "bom jornalismo" - na verdade, ao procurar repensar a produção de notícias e reportagens do seu ao redor, já era realizada uma forma de ativismo em si.

(publicado em 1984) ao qual reformula alguns dos alguns princípios já descritos em outros textos, como em 'Computer Lib/Dream Machines' por Theodor Nelson em 1974. As diretrizes dessa ética hacker acompanham a 'evolução' dos computadores para os dispositivos pessoais que usamos e confiamos hoje em dia, desenvolvendo tecnologias que permitam que estes sejam aprimorados, adaptados ou reutilizados em outros projetos. O ponto chave dessa vertente ética é o livre acesso a informações e a produção social do conhecimento livre, em função de uma produção colaborativa do código compartilhado, da tecnologia social e da ciência aberta" (DINIZ, 2017, p. 26) 


\section{ALCEU}

ISSN: 2175-7402

A escolha dos temas citados era fruto de reflexão sobre o próprio campo. Uma questão forte era a manutenção das formas violentas de exposição de pessoas e grupos. O que levava colegas - e a própria jornalista - a realizar enquadramentos repetitivos? E que caminhos poderiam ser seguidos para repensar tais representações? Tais reflexões, alinhadas a estratégias básicas do jornalismo, foram a fórmula para exercer esse engajamento. Reportagens como Ave Maria (2013), sobre o feminicídio visto a partir do assassinato de mulheres batizadas com o nome da mãe de Cristo, e Quase Brancos, Quase Pretos (2011), sobre racismo, foram confeccionadas a partir de uma intensa apuração, leitura de boletins de ocorrência, entrevistas, pesquisas em processos, vídeos. Tais reportagens mostraram que era possível realizar também esses esforços mesmo no seio de uma grande empresa (é claro que existem tempos e gestões diversas nessas questões que impedem ou estimulam tais práticas. Ainda assim, é possível encontrar estratégias de fissura). O que fica perceptível aqui - algo a ser trabalhado com mais intensidade em análises posteriores é que a própria pauta, o próprio recorte realizado pela reportagem, é em si uma ferramenta hacker. Hacker no sentido de trazer para o interior do jornalismo a possibilidade de novos enquadramentos, novas discussões, promover a complexidade já existente no cotidiano. Hacker no sentido de provocar o craquelamento de imagens/discursos do que parece natural, mas não é.

Os dois modelos - jornalismo comercial versus jornalismo ativista - mostravam, assim, que não precisavam estar desconectados. Importante dizer que analisar a própria produção não deve soar aqui como uma autorreferência: na proposta de um jornalismo de subjetividade, a teoria não pode ser apartada da prática, e refletir sobre o fazer é algo vital para entender que jornalismo está sendo realizado. É antes um exercício ético, no qual a/o jornalista não se neutraliza, mas pensa na potência e nos limites da própria produção. A técnica, afinal, é realizada, como lembra Veiga (2019), por um sujeito cognoscente. Todos nós somos orientados ideologicamente.

Essa prática ativista que, aqui, entendemos como contaminada por uma sensibilidade hacker, foi observada no trabalho de diversos jornalistas norte-americanos por Boynton (2005), que chamou de new new journalism a produção de autores e autoras norte-americanos de não ficção a partir do ano 2000. A referência ao novo jornalismo de Tom Wolfe, Gay Talese e outros é explícita, mas a diferença entre estes e aqueles é também clara e tem relação com uma forma engajada ou não engajada da prática noticiosa: no livro, Boynton traz uma dura fala do historiador Alan Trachtenberg sobre Wolfe, "que não tinha um único 
osso ativista em seu corpo": "Para Wolfe, o que importava era estilo, não política; prazer, não poder; status, não classe" (2005, p. 14). Falando sobre os escribas da virada do século 21, Boynton diz:

A sociedade é um fenômeno mais complexo para estes novos jornalistas do que foi para seus predecessores imediatos. Consideram classe e raça, e não status, os índices primários da hierarquia social. Subculturas étnicas e/ou ideológicas ("terra incógnita", como Wolfe as chamava) - uma vez percebidas como tribos bizarras que foram estudadas antropologicamente - são hoje consideradas diferentes em grau, não em espécie, do resto da cultura americana (BOYNTON, 2005, p. 12) ${ }^{5}$.

Na subjetividade que entende a prática ativista como pertinente ao bom jornalismo - aquele que procura informar para além do senso comum - não se nega a tomada de "um lado", como sugere o post do repórter do Correio Braziliense. Essa noção, inclusive, nos afasta da ideia de uma intersubjetividade no jornalismo, caminho proposto por De Melo (2007): segundo ela, esse jornalismo procura "não tomar partido", algo que feriria condutas técnicas éticas. A questão é que "tomar partido" é algo que está no DNA do jornalismo, e, se isso foi um dia declarado (como, por exemplo, nos jornais opinativos do século 19), passou a ser encoberto justamente pelo manto da objetividade. A pureza é um mito, como já sintetizou o artista Hélio Oiticica nos anos 60. Essa questão foi ventilada já a partir dos três movimentos necessários ao jornalismo e provocados pela dimensão subjetiva assumida:

Desde seu nascimento, o jornalismo massivo é permeado por interesses econômicos, ou seja, a isenção nunca foi uma característica dessa área de conhecimento. Apesar disso, insiste-se em realizar separações absurdas entre práticas "puras" enquanto outras, ao deixarem claros os propósitos de suas produções, são menos confiáveis. Poderíamos pensar justamente o contrário: acreditar preferencialmente em quem se revela e olhar com sérias restrições quem se antepara em lugares comuns como "apenas relatei os fatos" para esconder interesses específicos. Uma prática ativista não significa abrir mão de ferramentas e procedimentos vitais (apuração, pesquisa, produção polifônica), mas sim empregá-los em abordagens que, bem realizadas, respeitam e potencializam aquilo o que o jornalismo tem de mais poderoso: iluminar o que está sob as sombras. É vital compreender que o caminho da objetividade no jornalismo, para além dos procedimentos técnicos, deve ser guiado também pela percepção da sub-representação que atinge diversos grupos sociais, uma sub-representação, repito, causada também pelo jornalismo. Nesse bojo, acusar a presença da repórter e a partir de onde a mesma fala também é outra estratégia subjetiva assumida nesse método, uma vez que ela proporciona um melhor entendimento da construção própria que o jornalismo realiza de seus personagens. Quem está filtrando aquela vida para leitoras e leitores não está apagado, ao contrário. Não se trata de dar ênfase a um testemunho, mas acusar um processo de construção (ou seja, uma verdade entre muitas) (MORAES, 2018).

\footnotetext{
${ }^{5}$ Esta consideração se acopla também, como dito, a um dos fundamentos do que nomeamos como jornalismo de subjetividade: a superação comum no nascimento da própria antropologia, também no jornalismo, de enxergar grupos, pessoas e culturas como "o outro", o fora da normalidade, o extraordinário exótico. Tal enquadramento já sustentou representações miúdas e racistas, como, por exemplo, reconheceu a revista National Geographic ao fazer uma análise de sua produção ao longo de décadas https://www.nationalgeographicbrasil.com/cultura/2018/04/por-decadas-nossa-cobertura-foi-racista-parasuperarnosso-passado-temos-que (acesso em 24 de julho de 2019).
} 
A capacidade criativa da repórter precisa ser sublinhada, e cada encontro, único, produz o que Medina (1986) chama de interação social criadora, afinal o diálogo se dá sobretudo no nível da sensibilidade. Como genialmente sintetizou o cientista austríaco Heinz von Foerster, a objetividade é a ilusão de que as observações podem ser feitas sem um observador (CHRISTOFOLETTI, 2008). Esse caminho subjetivo e ativista precisa ser discutido, debatido, adensado, é claro. Mas, frente a um desmonte de credibilidade de um campo que em grande parte insiste em não refletir sobre si mesmo, já não é possível continuar empregando molduras anacrônicas para dar conta de uma sociedade que também se repensa. Há algo de muito errado em uma prática jornalística que não absorve os movimentos à sua volta em nome de uma "isenção".

Esta prática, aquela que privilegia um jornalismo declaratório, está virtualmente assentada no "apenas reportei os fatos" como se esse reportar, sem qualquer filtro, também não fosse uma forma de endosso ${ }^{6}$. A questão é pensar, para seguirmos ao final deste artigo, no que a objetividade, a isenção e um pretenso afastamento do ativismo da imprensa causou no tecido democrático brasileiro. Os rumos de forte perfume autoritário e antidemocrático que marcaram a vida política e social do Brasil nos últimos anos fizeram com que, de maneira mais explícita, a isenção jornalística da chamada grande imprensa fosse questionada, debatida.

Não se trata de uma observação exatamente nova: há décadas são realizadas pesquisas que investigam as propensões ideológicas do jornalismo moderno nacional, que nasceu fortemente sob o patrocínio de empresas privadas (SODRÉ, 1998). Mas há, sem sombra de dúvida, um ineditismo na atualidade que está relacionado ao espraiamento dessa discussão, uma popularização do papel e do discurso da imprensa entre uma população não acadêmica, o que é uma boa notícia. Esse fenômeno ganhou musculatura no Brasil principalmente a partir de 2013, quando milhões de pessoas foram às ruas, nos protestos conhecidos como Jornadas de Junho. Ali, assim como no Impeachment da ex-presidente Dilma Rousseff (PT) e, principalmente, nas eleições presidenciais de 2018, na qual se elegeu Jair Bolsonaro (PSL), a imprensa, sua cobertura e seus posicionamentos (quase sempre sem ousar dizer o nome) tornaram-se pauta diária de discussões que passaram além dos muros do conhecimento especializado.

\footnotetext{
${ }^{6}$ No dia 4 de setembro de 2018, a imprensa brasileira noticiou, com vídeo, o então candidato à presidência da república Jair Bolsonaro dizer, em comício no Acre, que iria "fuzilar a petralhada" enquanto segurava um suporte de microfone imitando uma arma. Assim como a revista Exame, cujo link está neste rodapé, uma série de outros veículos publicaram a mesma notícia trazendo a frase como título, sem qualquer análise, em nome da "isenção". Em https://exame.abril.com.br/brasil/vamos-fuzilarapetralhada-diz-bolsonaro-em-campanha-no-acre/. Acesso em 24 de julho de 2019.
} 


\section{ALCEU}

ISSN: 2175-7402

Foram também nesses momentos que se tornaram mais evidentes estratégias discursivas da imprensa em busca de, por exemplo, amenizar discursos de violência, discriminação, preconceito - na verdade, a própria imprensa historicamente os produziu, vide uma famosa capa da revista Placar trazendo o goleiro Bruno, na qual se preferiu falar da "morte" de Eliza Samudio, e não de seu assassinato. Tudo em nome de vender uma capa com um personagem "polêmico" ${ }^{7}$. A palavra polêmica, necessário dizer, foi uma das preferidas da imprensa nestes últimos anos, no qual o acirramento político desvelou discursos de ódio e intolerância, inclusive no campo institucional. $O$ atual presidente da República Jair Bolsonaro é uma das estrelas desse momento, sendo ele tratado como uma figura quase folclórica, apesar das frases misóginas e racistas que a imprensa não ousava nomear. Com esse cenário, entendemos que o momento é importante para reivindicar o que é jornalismo, complexificar sua deontologia, não a simplificar. Mostrar procedimentos, limites, resgatar o sujeito cognoscente ${ }^{8}$, não se entender como neutro, assumir as interpretações. Um bem maior que o individualismo: ter a noção de que o que fazemos tem impacto sobre a vida das pessoas. Ou se toma consciência disso, ou se continua a jogar como se fossem simplesmente valores universais os que são, antes, valores de empresas (VEIGA, 2019).

Fabiana Moraes

ORCID: https://orcid.org/0000-0001-8035-0163

Universidade Federal de Pernambuco, Núcleo de Design e Comunicação Social, Nova Caruaru (PE), Brasil.

Doutora em Sociologia pela UFPE

E-mail:fabimoraes@gmail.com

Recebido em: 31 de maio de 2020.

Aprovado em: 4 de setembro de 2020.

https://blogueirasfeministas.com/2014/04/28/a-capa-da-placar-com-bruno-faz-parte-da-normalidade-dofeminicidio-nobrasil/. Acesso em 24/05/2020

${ }^{8}$ Sujeito cognoscente, individualismo dentro do regime de verdade masculinista-capitalista; reconhecimento da subjetividade na interpretação da realidade, que é fundamental para um exercício ético responsivo (VEIGA, 2015) 


\section{Referências:}

ALBUQUERQUE, D. A. A atuação do WikiLeaks, de grupos hacktivistas e do Movimento Cypherpunk na reconfiguração do jornalismo investigativo. 2016. 109 p. Dissertação (Mestrado em Ciência da Computação) - Pós Graduação em Ciência da Computação, Universidade Federal de Pernambuco, Recife, 2016.

Disponível

em:

<https://repositorio.ufpe.br/bitstream/123456789/27079/1/DISSERTA\%c3\%87\%c3\%830\%20Dayane\%20A morim\%20Gon\%c3\%a7alves\%20de\%20Albuquerque.pdf> Acesso em: 15 set. 2020.

ANTOUN, H. Jornalismo e ativismo na hipermídia: em que se pode reconhecer a nova mídia. Revista FAMECOS, Porto Alegre, v. 8, n. 16, p. 135-148, 2008. Disponível em: <https://revistaseletronicas.pucrs.br/ojs/index.php/revistafamecos/article/view/3144> Acesso em: 15 set. 2020.

BOYNTON, R. The New New Journalism: conversations with Americas's Best Nonfiction Writers on Their Craft. New York: Vintage Books, 2005.

CHRISTOFOLETTI, R. A Medida do Olhar: objetividade e autoria na reportagem. 2008. 275 p. Tese (Doutorado em Ciências da Comunicação) - Escola de Comunicações e Arte, Universidade de São Paulo, São Paulo, 2008.

DE MELO, I. A. A defesa de uma nova objetividade jornalística: a intersubjetividade. Biblioteca On-line de Ciências da Comunicação, [s.l.]. 2007. Disponível em: <http://www.bocc.ubi.pt/pag/melo-isabelleintersubjectividade.pdf>. Acesso em: 20 jun. 2018

DIAZ, P. V. Devir-Hacker: empirismo, ética e ontologia na era informacional. 2017. 158 p. Dissertação (Mestrado em Ciência da Informação) - Instituto Brasileiro de Informação em Ciência e Tecnologia, Escola de Comunicação, Universidade Federal do Rio de Janeiro, Rio de Janeiro, 2017. Disponível em: <https://ridi.ibict.br/bitstream/123456789/959/1/IBICT Pedro DIAZ Dissertacao Mestrado .p.pdf>

Acesso em: 15 set. 2020.

GOUVEIA, D; MORAES, F. Para além do robô, a reportagem: pavimentando uma metodologia do jornalismo de subjetividade. In: MAIA, Marta; MARTINEZ, Monica (Orgs.). Narrativas midiáticas contemporâneas: perspectivas metodológicas. Rio Grande do Sul: Editora Catarse, 2018.

HARAWAY, D. Saberes localizados: a questão da ciência para o feminismo e o privilégio da perspectiva parcial. Cadernos Pagu, Campinas, n. 5, 7-41, 1995. Disponível em: <https://periodicos.sbu.unicamp.br/ojs/index.php/cadpagu/article/view/1773/1828> Acesso em: 15 set. 2020.

KUCINSK. B. Jornalistas e revolucionários: nos tempos da imprensa alternativa. Edusp: São Paulo, 2001. 
MEDINA, C. Ciência e jornalismo: da herança positivista ao diálogo dos afetos. São Paulo: Summus Editora, 2008.

$\begin{array}{lllll}\text {.Entrevista: } & \text { o diálogo } & \text { possível. } & \text { São }\end{array}$

MELO, S. Discursos e práticas: um estudo do jornalismo investigativo no Brasil. 2015. 150 p. Dissertação (Mestrado em Ciências da Comunicação) - Escola de Comunicação e Artes, Universidade de São Paulo, São Paulo, 2015. Disponível em: <http://teses.usp.br/teses/disponiveis/27/27152/tde-19092016155529/publico/SEANEALVESMELO.pdf> $\quad$ Acesso $\quad$ em: 15 set. 2020.

MORAES, F. O nascimento de Joicy: transexualidade, jornalismo e os limites entre repórter e personagem. Porto Alegre: Arquipélago 2015. Para que serve um jornalismo de subjetividade? In: ENCONTRO ANUAL DA ASSOCIAÇÃO BRASILEIRA DE PESQUISADORES EM JORNALISMO, 16., 2018, São Paulo. Anais [...] São Paulo: Associação Brasileira de Pesquisadores em Jornalismo, 2018 Disponível em: <http://sbpjor.org.br/congresso/index.php/sbpjor/sbpjor2018/paper/viewFile/1344/899>. Acesso em: 25 jul. 2019.

MORAES, D. Comunicação alternativa, redes virtuais e ativismo: avanços e dilemas. Revista de Economía Política de las Tecnologías de la Información y Comunicación, São Cristóvão-SE, v.9, n. 2, p. 1-20, 2007. Disponível em: <http://www.observatoriodaimprensa.com.br/download/Comunicacao alternativa.pdf> Acesso em: 15 set. 2020.

PRUDENCIO, K. Jornativismo: CMI e o ativismo online. Aurora Revista de Arte, Mídia e Política, [s.I.], n. 2, p. 68-79, jul. 2011. ISSN 1982-6672. Disponível em: <https://revistas.pucsp.br/aurora/article/view/6358> Acesso em: 15 set. 2020.

RUSSELL, A. Journalism as activism: recoding media power. Polity Press: Cambridge, 2016.

SODRÉ, N. W. História da imprensa no Brasil. Rio de Janeiro: Mauad Editora, 1998. TARGINO, M. G. Jornalismo cidadão: informa ou deforma? Brasília: IBICT: UNESCO, 2009. 258 p.

THOMPSON, JB. A mídia e a modernidade: uma teoria social da mídia. Petrópolis: Vozes, 1998

VEIGA, M. Entrevista concedida a Fabiana Moraes. Porto Alegre, 11 de junho de 2019. . Masculino, o gênero do jornalismo: modos de produção das notícias. Florianópolis: Insular: 2014. 


\section{Resumo}

A perspectiva ativista foi historicamente refutada por aquele que se notabilizou como o "bom jornalismo", este embebido pela ideia de objetividade. De acordo com o que é considerado senso comum, o ativismo macula ideologicamente o conteúdo noticioso, percepção também expressada nas publicações de jornalistas em redes sociais. A partir da ideia de um jornalismo de subjetividade, fazemos aqui uma reflexão sobre uma prática ativista que não se esconde como tal e que pode estar presente não só no que se entende como jornalismo independente/alternativo, mas ainda nas grandes empresas. Esta tomada de posição se dá, entre outros marcadores, pela reflexão sobre o próprio campo, pela não exotificação do outro e pela atuação de uma profissional que se sabe não neutra. Fazemos ainda uma análise das práticas jornalísticas associadas a uma "sensibilidade hacker" (RUSSEL, 2017), que pode e deve estar presente para além do uso de aparatos tecnológicos.

Palavras-chave: Subjetividade. Ativismo. Jornalismo. Sensibilidade hacker. Práticas.

\section{Abstract}

The activist perspective has historically been refuted by what has become known as "good journalism", which is imbued with the idea of objectivity. According to what is conceived as common sense, activism ideologically tarnishes news content, a perception also expressed in journalists' publications on social networks. Departing from the idea of subjectivity journalism, we propose here a reflection on an activist practice that does not hide itself as such and that can be present not only in what is understood as independent/alternative journalism, but also in large news companies. This position is argued, among other markers, through a reflection on the field itself, the non-exoticization of the other and the performance of a professional who understands herself as not neutral. We also make an analysis of the journalistic practices associated with a "hacker sensitivity" (RUSSEL, 2017), which can and must be present in addition to the use of technological devices.

Keywords: Subjectivity. Activism. Journalism. Hacker sensitivity. Practices. 


\section{Resumen}

La perspectiva activista ha sido históricamente refutada por lo que se conoce como "buen periodismo", imbuido de la idea de objetividad. Según lo que se considera sentido común, el activismo empaña ideológicamente el contenido de las noticias, una percepción también expresada en las publicaciones de los periodistas en las redes sociales. Basado en la idea del periodismo subjetivo, reflexionamos aquí sobre una práctica activista que no se esconde como tal y que puede estar presente no solo en lo que se entiende como periodismo independiente / alternativo, sino también en grandes empresas. Este posicionamiento se lleva a cabo, entre otros marcadores, debido a la reflexión sobre el campo en sí, la no exotización del otro y el desempeño de un profesional que sabe que no es neutral. También hacemos un análisis de las prácticas periodísticas asociadas con una "sensibilidad hacker" (Russel, 2017), que puede y debe estar presente además del uso de dispositivos tecnológicos.

Palabras clave: Subjetividad. Activismo. Periodismo. Sensibilidad de hacker. Prácticas.

Este artigo é publicado em acesso aberto (Open Access) sob a licença Creative Commons Attribution Non-Commercial (CC-BY-NC 4.0), que permite que outros remixem, adaptem e criem a partir do seu trabalho para fins não comerciais, e embora os novos trabalhos tenham de lhe atribuir o devido crédito e não possam ser usados para fins comerciais, os usuários não têm de licenciar esses trabalhos derivados sob os mesmos termos. 